\title{
Caracterização física e mecânica de blocos de concreto com incorporação de areia de resíduo de construção civil
}

\author{
Physical and mechanical characterization of \\ concrete blocks with the incorporation of sand \\ aggregate from construction waste
}

Danielle Melo Scheifer ${ }^{1}$, Ivan Julio Apolonio Callejas ${ }^{1}$

\begin{abstract}
${ }^{1}$ Universidade Federal de Mato Grosso, Departamento de Arquitetura e Urbanismo, Laboratório de Tecnologia e Conforto Térmico-LATECA, Av. Fernando Corrêa da Costa, nº 2367, CEP 78060-900, Mato Grosso, Cuiabá, Brasil e-mail: danischeifer@hotmail.com, ivancallejas1973@gmail.com
\end{abstract}

\section{RESUMO}

Em decorrência dos problemas ambientais gerados pelas disposições inadequadas de resíduos, o presente trabalho busca encontrar uma alternativa para a reciclagem dos resíduos de construção civil (RCC). Entre as aplicações possíveis, o agregado miúdo reciclado do RCC pode ser utilizado como um componente alternativo em substituição total ou parcial à areia artificial nas misturas cimentícias destinadas à produção de blocos de concreto (B). Assim, este trabalho objetiva analisar a viabilidade técnica sob o aspecto físico e mecânico do uso de agregados miúdos reciclados para a confecção de blocos para sistemas de vedação vertical. Utilizou-se o traço de referência 1:19,19 (cimento:agregados, em massa), no qual o agregado miúdo areia artificial foi progressivamente substituído por areia reciclada de RCC. Foram testadas as substituições nos teores de 25,50 e $100 \%$ de substituição de resíduo. As características físicas e mecânicas dos traços de concreto de referência e com substituição foram avaliadas segundo a norma NBR 12118:2013. Por meio do estudo de dosagem, buscou-se identificar o traço que incorporasse a maior quantidade de resíduos na mistura, mantendo o desempenho dentro dos limites estabelecidos pelas normas. O traço com 50\% de incorporação foi aquele que apresentou o melhor desempenho, com teor de absorção de água de 14,30\% e resistência média a compressão de 4,13MPa. Os Blocos de concreto da família 15x40 (dimensões de 140x190x390mm) produzidos com este teor de incorporação por meio de uso de máquina do tipo vibroprensa, apresentaram resistência à compressão característica de 3,21MPa e teor de absorção de água de 9,89\%, sendo classificados como Classe C, sem função estrutural. Desta forma, os agregados miúdos de origem de RCC são viáveis tecnicamente para serem incorporados em matrizes cimentícias para a produção de blocos de concreto, corroborando com a sustentabilidade urbana.

Palavras-chave: Agregado reciclado. Agregado miúdo. Sustentabilidade urbana. Blocos de concreto.

\begin{abstract}
Due to the environmental problems generated by inadequate waste disposal, this work seeks to find an alternative for recycling construction waste $(\mathrm{RCW})$. Among the possible applications, the recycled fine aggregate of RCW can be used as an alternative component in total or partial replacement to artificial sand in the cement mixtures designed for the production of the concrete blocks. Thus, this work aims to analyze the technical feasibility of the physical and mechanical aspects of the use of recycled fine aggregates for the production of concrete blocks for vertical panel systems. The reference trace 1:19.19 (cement: aggregates, by mass) was used in the dosage study, in which the industrial fine aggregate sand was progressively replaced by recycled construction waste sand. Substitutions were tested at 25, 50, and $100 \%$ of residue replacement. The physical and mechanical characteristics of reference and replacement concrete traces were evaluated according to Brazilian NBR 12118:2013 regulation. By the dosage study, it was sought to identify the dosage that incorporated the largest amount of residues in the mixture, maintaining the performance within the limits
\end{abstract}


established by the regulation. The dosage with $50 \%$ incorporation displayed the best performance, with a water absorption content of $14.30 \%$ and average compressive strength of $4.13 \mathrm{MPa}$. The $15 \times 40$ family concrete blocks, with dimensions of 140x190x390mm, produced with this dosage by the use of a Vibro press machine, displayed compressive strength characteristic of $3.21 \mathrm{MPa}$ and $9.89 \%$ of water absorption content, being classified as Class $\mathrm{C}$, without structural function. Therefore, the construction waste aggregates are technically feasible to be incorporated into cementitious matrices for concrete block production, corroborating with urban sustainability.

Keywords: Recycled aggregate. Fine aggregate. Urban sustainability. Concrete blocks.

\section{INTRODUÇÃO}

A indústria da construção civil (ICC) é um dos setores que mais gera emprego e renda, porém pelo viés ambiental, o impacto ocasionado por ela é de grande escala e magnitude: é responsável pelo consumo de $12 \%$ do total de água doce utilizável do planeta; a indústria do cimento responde por 5\% das emissões de gases de efeito estufa e pelo consumo de $33 \%$ da energia elétrica produzida, sendo que $40 \%$ de todos os resíduos gerados nas cidades provêm da construção civil [1]. A ICC ainda consome $32 \%$ de toda a energia global, sendo responsável por um quarto do total das emissões globais de $\mathrm{CO} 2$ [2], com destaque para seu parque edificado que consome $42 \%$ da energia produzida [3].

O gerenciamento responsável da enorme quantidade de resíduos sólidos gerados nas cidades, sejam eles industriais, comerciais, domésticos ou ainda provenientes do processo de construção e/ou demolição de edificações (denominados de resíduos de construção civil - RCC), tem sido um dos grandes desafios enfrentados pelos entes públicos municipais, estaduais e federal. A sua destinação quando conduzida de forma inadequada proporciona grandes impactos ambientais, causando poluição dos mananciais, assoreando de rios e córregos, contaminação do solo, obstrução dos sistemas de drenagem urbana, entre outros, contribuindo desta forma por onerar a administração pública municipal, órgão responsável pela remoção e disposição adequada desses resíduos [4]. No Brasil, apenas um teçco dos resíduos de construção e demolição são destinados adequadamente a aterros sanitários, enquanto o restante é disposto de forma irregular [5].

A reciclagem na construção civil pode gerar vários benefícios, com reflexo direto na redução no consumo de recursos naturais não renováveis, contribuindo diretamente para a solução de um dos principais objetivos de desenvolvimento sustentável da Agenda das Nações Unidas de 2030: assegurar padrões de produção e de consumo sustentáveis [6]. Nesse sentido, alternativas sustentáveis têm sido avaliadas em relação à utilização da fração inverte dos resíduos de construção civil como substituto dos agregados naturais em obras de pavimentação, na produção de argamassas, em sistemas de drenagem, em obras de contenção, tijolos e blocos de concreto para sistemas de vedação vertical, entre outros [7-10].

O bloco de concreto (BC) é a unidade de alvenaria, constituído por mistura homogeneizada, usualmente composta por materiais como o cimento Portland, agregado miúdo, agregado graúdo, água e aditivos, moldado por meio de vibração e prensagem simultâneas [11]. Estes insumos são adequadamente dosados visando à produção de um "concreto seco" destinado a fabricação de BC para alvenaria estrutural e de vedação. São classificados de acordo com seu uso, em termos de requisitos mínimos de resistência característica à compressão axial $\left(\mathrm{f}_{\mathrm{b} k}\right)$ e porcentagens de absorção de água (\%): a) Classe A, com função estrutural, para uso em elementos de alvenaria $-\mathrm{f}_{\mathrm{bk}} \geq 8 \mathrm{MPa}$ e porcentagem de absorção de água individual do bloco e média menor ou igual a $9 \%$ e $8 \%$, respectivamente ; b) Classe B, com função estrutural, para uso em elementos de alvenaria acima do solo $-4 \mathrm{MPa} \leq \mathrm{f}_{\mathrm{bk}}<8 \mathrm{MPa}$ e porcentagem de absorção de água individual do bloco e média menor ou igual a $10 \%$ e $9 \%$, respectivamente; e, c) Classe C, com ou sem função estrutural, para uso em elementos de alvenaria acima do solo $-\mathrm{f}_{\mathrm{b}} \geq 3 \mathrm{MPa}$ e porcentagem de absorção de água individual do bloco e média menor ou igual a $11 \%$ e $10 \%$, respectivamente. Para agregado leve, os valores de porcentagens de absorção de água individual e média se reduzem para $16 \%$ e 13\%, respectivamente. As tolerâncias permitidas nas dimensões dos blocos são de $\pm 2,0 \mathrm{~mm}$ para largura, $\pm 3,0 \mathrm{~mm}$ para a altura e comprimento, enquanto a área líquida do BC deve ser igual ou inferior a 75\% da área bruta [11].

Pesquisas recentes têm focado na incorporação de resíduos nas misturas destinadas a confecção dos BC visando não só aperfeiçoar a suas propriedades físicas, mecânicas e térmicas, mas também produzir materiais mais sustentáveis, que ajudem a reduzir a enorme quantidade de resíduos sólidos gerados. Entre os utilizados para a produção dos BC, tem-se os resíduos orgânicos proveniente do desdobro de toras de Pinus spp, de serragem, de casca de arroz e de papel reciclado [12-15], resíduos minerais oriundos de lodo de Estação de Tratamento de Água, de granito, de escória de aciaria, de areia de fundição, de vidro e de material isolante [1621], resíduos poliméricos de EVA (etileno acetato de vinila), de borracha de pneu e de PET (polietileno tereftalato) [22- 25], resíduo do próprio BC [26] e resíduos de agregados reciclados de RCC [27-32]. Uma revisão 
sistemática sobre o tema pode ser consultada em [33].

Diante das potencialidades observadas nas pesquisas apresentadas, este trabalho foca no reaproveitamento dos resíduos oriundos da construção civil como medida de mitigação ambiental, visando não só reduzir a extração de recursos naturais, mas também em evitar a geração de materiais para descarte. Por outro lado, busca-se um alinhamento entre tecnologia e processos com vistas a minimizar os impactos negativos da construção civil. Assim, este trabalho objetiva analisar a viabilidade técnica sob o aspecto físico e mecânico do uso de agregados miúdos de areia reciclada para a confecção de blocos de concreto para sistemas de vedação verticais. Como contribuição do estudo, além de preencher a lacuna no conhecimento sobre o tema, o sistema de vedação vertical com blocos de concreto com incorporação de areia de RCC contribui para assegurar padrões de produção e de consumo sustentáveis.

\section{MATERIAIS E MÉTODOS}

A pesquisa se desenvolve em parceria com uma indústria de produção de artefatos de concreto. Desta forma, utilizou-se no estudo de dosagem e na produção dos blocos de concretos os seguintes materiais disponibilizados pela empresa: areia artificial, brita 0 , pó de pedra, cimento, água e aditivo plastificante. Além destes, utilizou-se o agregado miúdo de areia de resíduo de construção (RCC) em substituição parcial ao de areia artificial para a produção dos blocos de concreto. A caracterização dos materiais, das propriedades físicas e mecânicas dos traços e blocos de concreto produzidos sem e com substituição de areia de resíduo de construção, seguiu o fluxograma indicado na Figura 1.

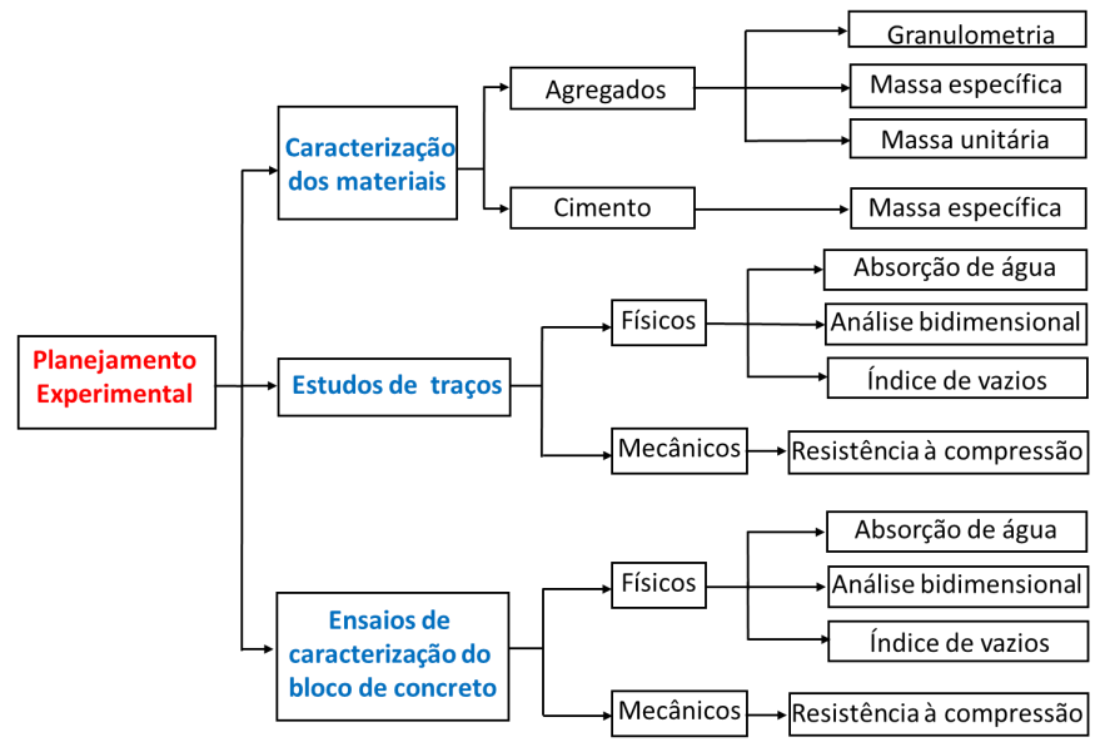

Figura 1: Fluxograma do planejamento experimental da pesquisa.

\subsection{Materiais}

\subsubsection{Agregados}

Os agregados graúdos (brita), miúdos (areia) e o pó-de-pedra utilizados na produção dos blocos de concreto foram os artificiais, de origem do granito róseo, extraídos na Serra de São Vicente, localizada à $60 \mathrm{~km}$ da cidade de Cuiabá-MT, Brasil. A areia de RCC, caracterizada com sendo um agregado de fração vermelha predominante, é proveniente da uma recicladora instalada no perímetro urbano da cidade onde ocorre a pesquisa.

Com a finalidade de caracterizar as propriedades físicas dos agregados utilizados no estudo dos traços e na moldagem dos blocos de concreto, amostras de areia artificial, areia de RCC, pedrisco e pó de pedra foram submetidos a ensaios de análise granulométrica [34], massa unitária no estado solto [35] e massa específica $[36,37]$. Para a realização dos ensaios descritos acima, realizou-se o processo de redução das amostras seguido pela norma NBR NM 27 [38].

As propriedades físicas dos materiais utilizados como insumos para a produção do bloco podem ser observadas na Tabela 1 e na Figura 2. O módulo de finura da areia artificial é 2,16, caracterizando-a como fina, 
com curva granulométrica dentro da zona ótima segundo a NBR 7211 [39]. O mesmo ocorreu com a areia reciclada de RCC, também caracterizada como areia fina, com módulo de finura de 2,46. Nota-se que a composição granulométrica obtida para a areia de resíduo apresenta uma melhor distribuição do que a areia artificial. Ambas apresentam densidade específicas muito próximas uma da outra, porém a absorção de água por parte da areia reciclada $(11,1 \%)$ é muito superior ao da areia artificial $(1,5 \%)$, fator que pode influenciar o fator água/ cimento de concretos com a utilização desse tipo de insumo.

O módulo de finura do pó de pedra é de 2,55, com curva granulométrica inserida dentro dos limites de zona ótima [39]. Já o pedrisco apresenta mais que $2 \%$ de material passante na peneira de abertura de malha de 4,75. A sua curva granulométrica se encontra fora dos limites da zona granulométrica, optando-se por mantê-lo, em função de ser o único disponibilizado pela empresa fabricante do bloco.

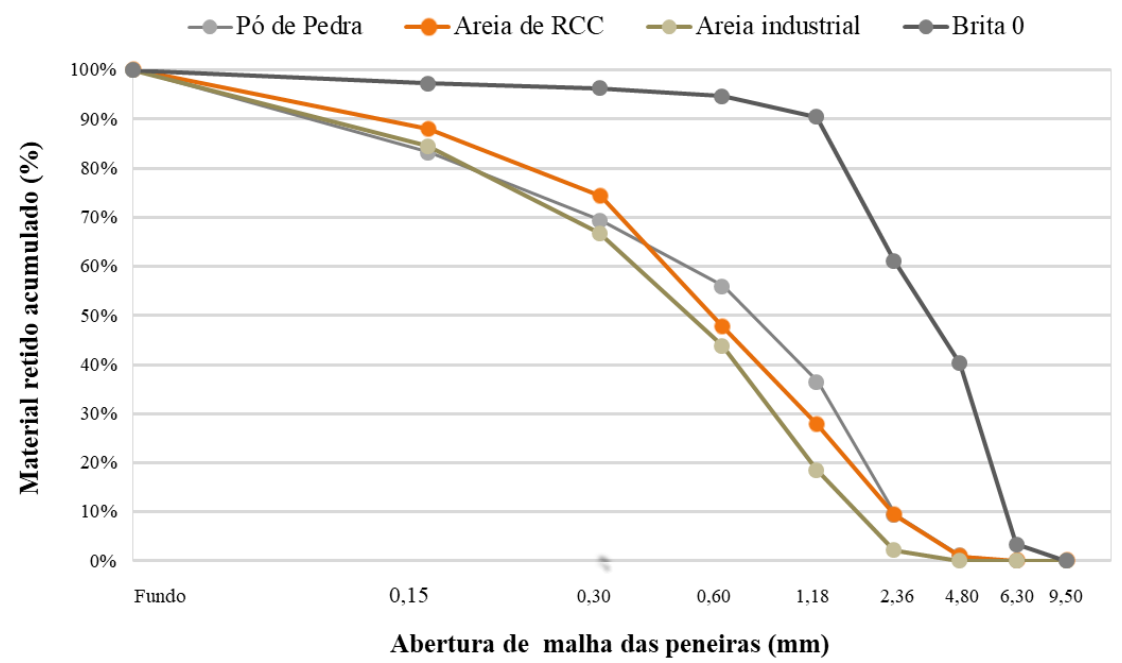

Figura 2: Curvas granulométricas do insumo pó-de-pedra, areia de RCC, areia industrial e brita 0.

Tabela 1: Ensaios de caracterização dos agregados miúdos e graúdos.

\begin{tabular}{|c|c|c|c|}
\hline AGREGADO & ENSAIOS & VALORES OBTIDOS & FOTO \\
\hline \multirow{4}{*}{ AREIA ARTIFICIAL } & Massa específica $\left(\mathrm{g} / \mathrm{cm}^{3}\right)$ & 2,120 & \\
\hline & Massa aparente (solta) $\left(\mathrm{g} / \mathrm{cm}^{3}\right)$ & 1,134 & \\
\hline & Diâmetro máximo característico (mm) & 2,36 & \\
\hline & Módulo de finura & 2,16 & \\
\hline \multirow{4}{*}{ AREIA DE RCC } & Massa específica $\left(\mathrm{g} / \mathrm{cm}^{3}\right)$ & 2,200 & \\
\hline & Massa aparente (solta) $\left(\mathrm{g} / \mathrm{cm}^{3}\right)$ & 1,367 & \\
\hline & Diâmetro máximo característico (mm) & 4,75 & \\
\hline & Módulo de finura & 2,48 & \\
\hline \multirow{4}{*}{ PÓ DE BRITA } & Massa específica $\left(\mathrm{g} / \mathrm{cm}^{3}\right)$ & 2,200 & \\
\hline & Massa aparente (solta) $\left(\mathrm{g} / \mathrm{cm}^{3}\right)$ & 1,367 & \\
\hline & Diâmetro máximo característico (mm) & 4,75 & \\
\hline & Módulo de finura & 2,55 & \\
\hline \multirow{4}{*}{ BRITA 0} & Massa específica $\left(\mathrm{g} / \mathrm{cm}^{3}\right)$ & 2,040 & \\
\hline & Massa aparente (solta) $\left(\mathrm{g} / \mathrm{cm}^{3}\right)$ & 1,155 & \\
\hline & Diâmetro máximo característico (mm) & 9,5 & \\
\hline & Módulo de finura & 5,42 & \\
\hline
\end{tabular}




\subsubsection{Aglomerante}

Empregou-se o cimento Portland CPV ARI, o mesmo utilizado pela indústria parceira da pesquisa em virtude da sua alta resistência inicial, atendendo a necessidade dos BC serem manuseados em poucos dias após a sua confecção. Para a determinação da massa específica do cimento, utilizou-se o Frasco de Le Chatelier, conforme NBR NM 23 [40] e para determinação da massa aparente (solta), utilizou-se uma adaptação dos procedimentos da NBR NM 45 [35]. Na Tabela 2, apresentam-se os valores de massa específica e aparente (solta).

Tabela 2: Caracterização do Cimento Portland CPV ARI (Alta Resistência Inicial).

\begin{tabular}{l|l}
\hline ENSAIOS & PROPRIEDADE \\
\hline Massa específica $\left(\mathrm{g} / \mathrm{cm}^{3}\right)$ & 3,180 \\
\hline Massa aparente (solta) $\left(\mathrm{g} / \mathrm{cm}^{3}\right)$ & 1,225 \\
\hline
\end{tabular}

\subsubsection{Aditivo plastificante e água para dosagem}

$\mathrm{Na}$ produção dos BC, utilizou- se um aditivo plastificante (base surfactante, características - ph 12-13, densidade $1-1,03 \mathrm{~g} / \mathrm{cm}^{3}$ e viscosidade 120 - $350 \mathrm{cSt}$ ) para concretos secos, que tem a função de dar maior fluidez a massa, elevar o grau de compactação das peças e reduzir a absorção de água pela mistura. A água usada para produção dos blocos de concreto foi a proveniente da rede de abastecimento local (Águas Cuiabá), considerada potável, seguindo as recomendações da NBR 15900 [41].

\subsection{Métodos}

\subsubsection{Etapa 1 - Definição e Elaboração dos traços de concreto para produção de blocos de vedação}

Com o intuito de avaliar o impacto da substituição da areia artificial pela de RCC, definiu-se que as misturas ou traços seriam utilizados para confeccionar blocos de concreto nas dimensões $14 \times 19 \times 39 \mathrm{~cm}$, pertencentes a família 15x40. Outro critério estabelecido é que a dosagem do concreto dos blocos deveria ser capaz de atender a resistência mínima e absorção máxima requerida para a classe $\mathrm{C}$, sem função estrutural, ou seja, resistência compressão característica superior a $3 \mathrm{MPa}$ e absorção de água inferior a $10 \%$. Considerou-se ainda que os blocos seriam produzidos por meio de vibroprensagem, com equipamento operado no canteiro de uma fábrica comercial, atendendo os requisitos da NBR 6136 [11].

Como a pesquisa foi desenvolvida com a ajuda de uma empresa de produção de artefatos de concreto, utilizou-se como referência para a pesquisa o traço utilizado pela mesma na proporção de 1:19,19 ou seja, para cada $1 \mathrm{~kg}$ de cimento foram utilizados $19,19 \mathrm{~kg}$ de agregados em massa para produzir blocos que alcancem 4,0 MPa (sem incorporação de RCC). O traço de referência foi utilizado para a dosagem dos traços com substituição parcial de areia natural por de RCC.

Preliminarmente, conduziu-se levantamento de algumas pesquisas sobre o tema, onde se pode perceber que a incorporação de resíduos de RCC proporciona redução da resistência mecânica nos traços de concretos à medida que se eleva as frações de substituição do resíduo na massa (sejam eles miúdos ou graúdos) [33]. Assim, a primeira etapa da pesquisa foi conduzida em laboratório, onde se procurou compreender o comportamento da substituição da areia industrializada pela de RCC. Para tanto, definiu-se três porcentagens de substituição para a matriz cimentícia do bloco: uma com $25 \%$, outra com $50 \%$ e finalmente $100 \%$ de substituição, considerando que a massa ocupada pela areia industrial no interior do concreto passará a ser ocupada por massa das partículas de RCC, em virtude da proximidade dos valores de massa específica destes agregados. A partir do traço de referência, calculou-se a substituição de areia por resíduo de RCC nos teores de $25 \%$, $50 \%$ e $100 \%$, mantendo-se o volume. Procurou-se manter o fator água/cimento inalterado, mas devido a maior absorção de água por parte do resíduo de RCC, em razão da alta taxa de incorporação da areia reciclada, pela presença de materiais argilosos provenientes principalmente de resíduos de blocos cerâmicos, houve a necessidade de se reajustar a quantidade de água nos traços de 50 e $100 \%$ de substituição com vistas a se obter uma massa com adequada trabalhabilidade. O ajuste também se fez necessário em outros estudos [27, 42].

O cálculo da substituição do agregado de resíduos utilizou-se da Equação 1, em que $\mathrm{M}_{\mathrm{r}}$ é a massa de resíduo a ser utilizada no traço $(\mathrm{g}) ; \mathrm{V}(\%)$ o percentual de areia a ser substituído pelo resíduo; $\mathrm{M}_{\mathrm{a}}$ a massa total de areia no traço $(\mathrm{g}) ; \gamma_{\mathrm{a}}$ a massa específica da areia $\left(\mathrm{g} / \mathrm{cm}^{3}\right)$ e $\gamma_{\mathrm{r}}$ a massa específica do resíduo $\left(\mathrm{g} / \mathrm{cm}^{3}\right)$.

$$
M_{r}=V(\%) \cdot \frac{M_{a} \times y_{r}}{y_{a} \times 100}
$$


A Tabela 3 ilustra o quantitativo de cada insumo utilizado nos traços, expressos em massa (gramas).

Tabela 3: Proporção em massa dos agregados utilizados para a produção dos traços em gramas.

\begin{tabular}{|c|c|c|c|c|c|c|c|c|}
\hline \multicolumn{9}{|c|}{ COMPOSIÇÃO DOS TRAÇOS ADOTADOS NA PESQUISA } \\
\hline & Cimento & Areia & Brita & Pó de pedra & Água & Aditivo & $\begin{array}{l}\text { Areia de } \\
\text { RCC }\end{array}$ & $\begin{array}{l}\text { Cimento: Agregado } \\
\text { Miúdo: Resíduo }\end{array}$ \\
\hline Traço de referência & 291 & 3080 & 1090 & 1420 & 412,4 & 8,74 & 0 & 1:19,19:0,00 \\
\hline Traço $\mathrm{RCC} 25^{\mathrm{a}}$ & 291 & 2310 & 1090 & 1420 & 412,4 & 8,74 & 770 & $1: 16,56: 2,64$ \\
\hline Traço RCC50 ${ }^{\mathrm{b}}$ & 291 & 1155 & 1090 & 1420 & 512,4 & 8,74 & 1155 & $1: 13,91: 5,29$ \\
\hline Traço RCC100 ${ }^{\mathrm{c}}$ & 291 & 0 & 1090 & 1420 & 612,4 & 8,74 & 1155 & $1: 8,62: 10,58$ \\
\hline \multicolumn{9}{|c|}{${ }^{\mathrm{a}}$ Traço 1 - Substituição da areia industrial por areia de RCC em $25 \%$} \\
\hline \multicolumn{9}{|c|}{${ }^{\mathrm{b}}$ Traço 2 - Substituição da areia industrial por areia de RCC em 50\% } \\
\hline \multicolumn{9}{|c|}{${ }^{\mathrm{c}}$ Traço 2 - Substituição da areia industrial por areia de RCC em $100 \%$} \\
\hline \multicolumn{9}{|c|}{${ }^{\mathrm{d}}$ Traço 2 e 3 - ajuste de água visando adequar a trabalhabilidade da massa para a produção do bloco } \\
\hline
\end{tabular}

Fonte: Autor

Foram confeccionados de forma manual 12 corpos de prova para cada traço (o de referência - sem adição de RCC, mais os traços com incorporação de RCC - em 25, 50 e 100\%, doravante denominados RCC25, RCC50 E RCC100, respectivamente) (Figura 3a). A moldagem ocorreu em moldes cilíndricos de 5x10cm, pré-lubrificados, onde a mistura foi compactada em quatro camadas de 30 golpes. A desmoldagem ocorreu após 24 horas (Figura 3b), e os blocos foram submersos em água para a cura, até a realização dos ensaios de absorção, índice de vazios, densidade e resistência à compressão aos 7, 14 e 28 dias.

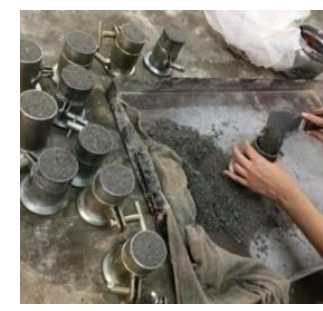

a)

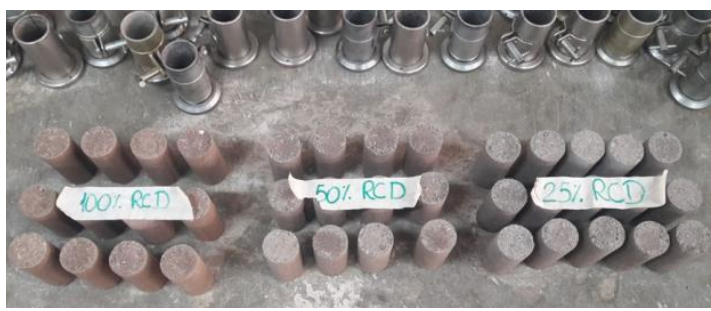

b)

Figura 3: a) Processo de moldagem dos CPs; b) CPS dos traços de 25\%, $50 \%$ e $100 \%$ de RCC.

Definidos os traços, realizaram-se os ensaios de massa específica ( $\rho$ ) (Equação 2), absorção de água $(\alpha)$ (Equação 3) e índice de vazios (Iv) (Equação 4) em três corpos de prova para cada traço (12 CPs), conforme as Equações 2, 3 e 4. Primeiramente, realizou-se a secagem do corpo de prova por meio de estufa na temperatura de até $\left(110 \pm 5^{\circ} \mathrm{C}\right)$ por $24 \mathrm{~h}$ e registrada a pesagem dessa massa seca $(\mathrm{m} 1)$. Na sequência, com os corpos de prova em temperatura ambiente, foram imersos em água à temperatura de $\left(23 \pm 5^{\circ} \mathrm{C}\right)$ durante $24 \mathrm{~h}$, após o que foram secos superficialmente e pesados na condição de saturado com superfície seca $(\mathrm{m} 2)$. Finalmente, foi determinada a massa do corpo de prova quando imerso em água $(\mathrm{m} 3)$ à temperatura de $\left(23 \pm 5^{\circ} \mathrm{C}\right)$ por meio de balança hidrostática.

$$
\begin{aligned}
& \rho=\frac{m 1}{m 1-m 3} \\
& a(\%)=\frac{m 2-m 1}{m 1} \times 100 \\
& I v(\%)=\frac{m 2-m 1}{m 2-m 3} \times 100
\end{aligned}
$$

Todos os ensaios previamente apresentados tiveram seus valores representados por meio de média e 
desvio padrão por meio de três determinações em cada traço confeccionado. O ensaio de resistência à compressão axial foi executado em três corpos de prova de cada traço pesquisado, nas idades de 7, 14 e 28 dias. O ensaio ocorreu em laboratório com utilização de uma prensa hidráulica para mensurar a carga de ruptura suportada pelos traços de concreto. Para execução do ensaio, os CPs foram previamente retirados do tanque de cura, secos e posicionados longitudinalmente na prensa de forma centralizada com os pratos da prensa. Por fim, foram submetidos a uma carga crescente, em toneladas, com uma velocidade constante até seu momento de ruptura. $\mathrm{O}$ valor da resistência de cada traço será representado por meio de média simples e desvio padrão através de três determinações para cada traço produzido.

Para a próxima etapa, apenas o traço que apresentou a maior percentagem de incorporação de RCC e que atendeu aos requisitos normativos de desempenho físico-mecânico, foi utilizado. Com essa estratégia, busca-se absorver e/ ou reduzir o passivo ambiental da cadeia produtiva da Construção Civil, procurando minimizar sua destinação para áreas ilegais ou aterros sanitários.

\subsubsection{Etapa 2 - Ensaios de Caracterização dos blocos de concreto}

Definida a porcentagem de RCC ideal de incorporação, deu-se sequência à produção dos blocos de concreto do tipo vazado, fabricados nas dimensões 140x190x390mm (família M-15), produzidos em uma vibroprensa (Figura 4).

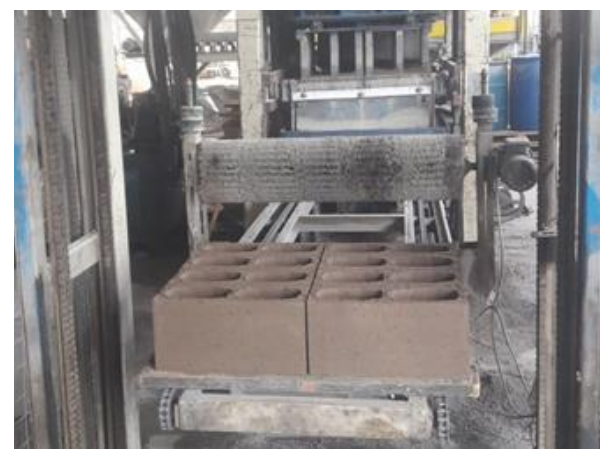

Figura 4: Desforma dos blocos após a sua produção em fábrica.

Os blocos de concreto necessitam atender aos requisitos técnicos de absorção de água, massa específica, índice de vazios, análise dimensional, área líquida e ensaio de compressão axial, com vistas a torná-los adequados à comercialização.

Os ensaios de absorção de água, massa específica, índice de vazios e área líquida foram realizados em três blocos de concreto para cada traço. Para isso, procedeu-se a secagem do corpo de prova por meio de estufa na temperatura de até $\left(110 \pm 5^{\circ} \mathrm{C}\right)$ e mantida essa condição por $24 \mathrm{~h}$. Na sequência, registrou-se por meio de pesagem a massa seca $(\mathrm{m} 1)$ e, com os blocos em temperatura ambiente, os blocos foram imersos em água à temperatura de $\left(23 \pm 5^{\circ} \mathrm{C}\right)$ durante $24 \mathrm{~h}$. Conduzida esta etapa, os blocos foram secos superficialmente, pesados na condição de saturado com superfície seca $(\mathrm{m} 2)$ e imersos em água $(\mathrm{m} 3)$, por meio de balança hidrostática.

Para obtenção dos resultados da massa específica, absorção de água e índice de vazios, utilizaram-se as Equações 2, 3 4, citadas anteriormente. O cálculo da área líquida de cada bloco $\left(\mathrm{A}_{\mathrm{liq}}\right)$, expressa em $\mathrm{cm}^{2}$, foi feita utilizando-se a Equação 5, em que $\gamma$ é a massa específica da água utilizada no ensaio, expressa em $\mathrm{g} / \mathrm{cm}^{3}$; h é a altura média do corpo de prova medida na direção perpendicular à seção de trabalho, expressa $\mathrm{em} \mathrm{cm}$.

$$
\text { Aliq }=\frac{m 2-m 3}{h \times \gamma} \times 1000
$$

Para o ensaio de análise dimensional foram coletadas as dimensões de seis blocos de concreto de cada traço: largura (b); altura (h); comprimento (l); espessura das paredes longitudinais (el); espessura das paredes transversais (et); dimensões dos furos. O valor de cada dimensão do corpo de prova foi resultado da média de três determinações executadas em pontos distintos. Para a espessura das paredes foram realizadas duas de- 
terminações em cada parede longitudinal e uma determinação em cada parede transversal, tomadas na face de menor espessura. Para as dimensões dos furos foram retiradas duas determinações no centro aproximado de cada furo do bloco, na direção longitudinal e transversal, tomadas na face de maior espessura do bloco. A espessura mínima da parede longitudinal é resultado da média das determinações feitas no bloco. O cálculo da área bruta foi calculado pelo produto do valor médio das dimensões obtidas de largura e comprimento, sem desconto das áreas dos furos ou reentrâncias. As dimensões foram aferidas com precisão de $1 \mathrm{~mm}$ por meio de uso de paquímetro metálico calibrado.

O ensaio de resistência à compressão axial foi executado em seis blocos de cada traço, nas idades de 14 e 28 dias seguindo os procedimentos estabelecidos NBR 6136 [11]. Antes da realização do ensaio foi necessário capear os blocos de concreto, para regularização das faces e melhor distribuição das cargas aplicadas sobre os blocos no momento do ensaio de resistência a compressão. A tensão de ruptura dos blocos (MPa) foi determinada conforme a NBR 12118 [43]. Os valores característicos da resistência a compressão dos blocos de concreto (MPa) foram calculados de acordo com a NBR 6136 [11].

\section{RESULTADOS E DISCUSSÃO}

\subsection{Etapa 1 - Estudo dos Traços}

$\mathrm{O}$ traço de referência foi aquele que proporcionou maior massa específica aparente para os traços pesquisados (Tabela 4). Entre os híbridos, observou-se incialmente redução da massa específica para o teor de substituição de $25 \%$, com posterior elevação no teor de $50 \%$, e queda no de $100 \%$ de substituição. A elevação da massa específica está atrelada ao maior entrosamento entre as partículas, trazendo como consequência uma possível redução no índice de vazios e de absorção de água na matriz cimentícia. De fato, observa-se comportamento similar nos ensaios físicos de teor de absorção de água e índice de vazios, com menores valores sendo observado na mistura híbrida com $50 \%$ de teor de substituição. As maiores taxas de absorção de água e de índices de vazios nessas misturas é explicado pela presença de materiais triturados de cerâmica, gesso, argamassa, concreto, entre outros resíduos presentes na areia de RCC que apresentam maior porosidade que a areia natural, o que favorece a retenção de umidade na matriz cimentícia.

Em nenhum dos traços pesquisados, inclusive o de referência, foi atendido o requisito normativo estabelecido pela NBR 6136 [11] de 10\% de absorção de água. No entanto, espera-se que esta não conformidade identificada no estudo de dosagem seja eliminada durante a fase de produção dos blocos uma vez que eles são produzidos por meio de processo de vibroprensagem. Portanto, sob o aspecto físico, recomenda-se que sejam fabricados blocos de concreto com $50 \%$ de substituição, uma vez que este apresentou o melhor desempenho entre as misturas pesquisadas.

Tabela 4: Valores médios e desvio padrão para as propriedades físicas dos traços pesquisados.

\begin{tabular}{c|c|c|c}
\hline TRAÇO & $\begin{array}{c}\text { MASSA ESPEC. SECA } \\
\left(\mathbf{g} / \mathbf{c m}^{3}\right)\end{array}$ & ABSORÇÃO (\%) & $\begin{array}{c}\text { ÍNDICE DE VAZIOS } \\
(\%)\end{array}$ \\
\hline RF & $1,88 \pm 0,0317$ & $11,42 \pm 0,059$ & $21,45 \pm 0,081$ \\
\hline $25 \%$ & $1,68 \pm 0,0381$ & $15,38 \pm 0,076$ & $25,84 \pm 0,076$ \\
\hline $50 \%$ & $1,73 \pm 0,0621$ & $14,30 \pm 0,109$ & $24,69 \pm 0,109$ \\
\hline $100 \%$ & $1,70 \pm 0,0193$ & $16,59 \pm 0,040$ & $28,13 \pm 0,040$ \\
\hline
\end{tabular}

Quanto ao ensaio mecânico, nota-se elevação da resistência média à compressão axial em todos os traços pesquisados para todas as idades ensaiadas (Figura 5). Porém, para o traço RCC25 e RCC100, observa-se redução de resistências em relação à do traço referência (RF). Já o traço RCC50 apresentou o melhor desempenho tanto em relação aos traços híbridos quanto em relação ao de RF para todas as idades, com elevação de 4\% aos 28 dias de idade em relação ao último. A análise estatística aos 28 dias de idade indicou que há diferença significativa entre o traço de referência e os demais traços com incorporação de $\mathrm{RCC}(\mathrm{p}<0,05)$. BASTOS el al. [28] em estudo de substituição de $100 \%$ da areia natural por areia de RCC (agregado miúdo passante na peneira 4,2mm) constataram comportamento semelhante ao obtido nesta pesquisa, com elevação da resistência a compressão aos 28 dias em relação ao traço de referência. 


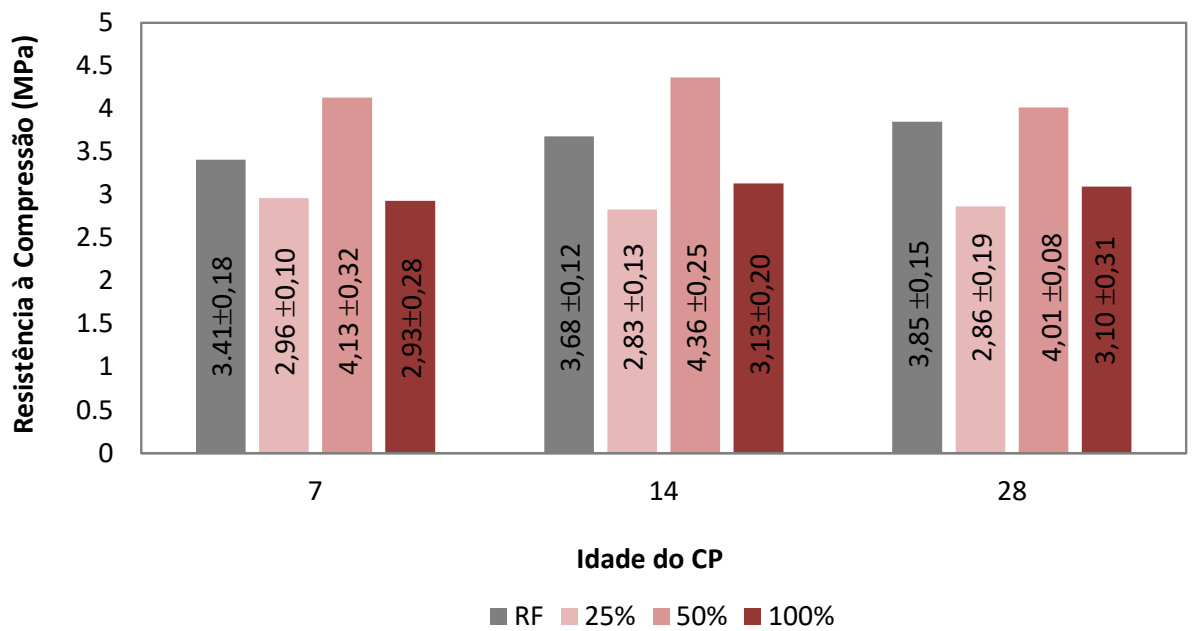

Figura 5: Resistência à compressão médiałdesvio padrão dos CPs em função do traço e da idade.

Ao se relacionar o teor de substituição com a respectiva resistência à compressão média nas várias idades (Figura 6), é possível perceber que há uma tendência de elevação da resistência com o aumento da substituição até certo limite, ocorrendo posteriormente um decaimento da mesma. Isso indica que deve haver um teor ótimo de substituição, possibilitando utilizar uma porcentagem ainda maior de RCC para a produção do bloco (entre 60 e 65\%). No entanto, para se comprovar este efeito, novos ensaios necessitariam ser conduzidos. CARDOSO [8] encontrou valores de resistência para argamassa com resíduos de RCC de 5,4MPa com incorporação de $10 \%$ de RCC, 5,9MPa com $20 \%$ RCC, 5,9MPa para 30\% e 5,7MPa para mistura composta por $40 \%$ RCC. O autor percebeu que a partir de $40 \%$ de adição de resíduos na mistura, a resistência diminui, comportamento não observado neste trabalho.

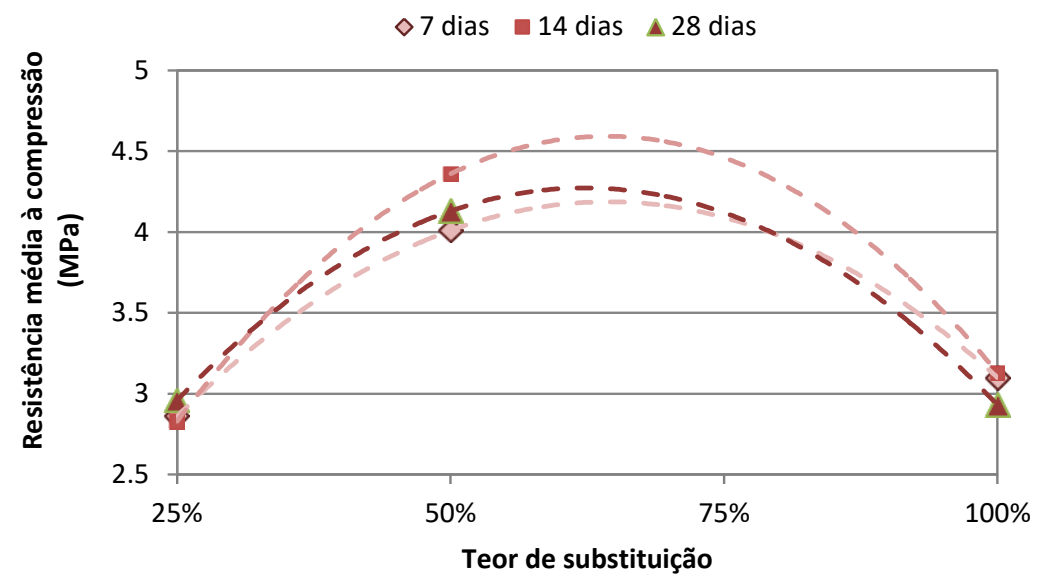

Figura 6: Relação de resistência à compressão com o teor de substituição de RCC.

Com relação ao requisito mecânico requerido para os traços, nota-se, que aqueles com substituição, de $50 \%$ e $100 \%$ de RCC apresentam potencialidade para alcançar o valor limite normativo ( $\geq 3,0 \mathrm{MPa}$ ). Como o traço com $100 \%$ de RCC apresentou resistência muito próxima ao limite, este foi descartado uma vez que a norma utiliza a estimativa da resistência característica como critério de desempenho dos blocos e não o valor médio, como calculado anteriormente. Assim, diante dos resultados, selecionou-se o traço que apresenta 50\% de substituição da areia industrial uma vez que ele incorpora maior quantidade de resíduos e que apresenta adequado desempenho mecânico para ser utilizado para a fabricação dos blocos, apesar do teor de absorção de água ter sido superior ao recomendado pela norma (10\%). No entanto, acredita-se que, como os corpos de prova foram produzidos manualmente em laboratório, o processo de vibroprensagem utilizado em fábrica possa promover ainda mais o adensamento da massa do concreto, trazendo este índice físico para dentro dos limites da norma. Portanto, os blocos de concreto foram confeccionados com este traço. 


\subsection{Etapa 2 - Ensaios de Caracterização dos blocos de concreto}

A Tabela 5 ilustra os valores obtidos nas medições das dimensões dos blocos, pesquisados, de onde se pode concluir que todos os blocos com dimensões nominais de $140 \mathrm{~mm}$ x $190 \mathrm{~mm}$ x $390 \mathrm{~mm}$ (largura, altura e comprimento) satisfazem os requisitos da NBR 6136 [11], no qual especifica uma tolerância máxima de \pm $2 \mathrm{~mm}$ para a largura e $\pm 3 \mathrm{~mm}$ para altura e para o comprimento. Portanto, os blocos se enquadram na família $15 \times 40$, classe $C$, sem função estrutural.

Acerca da área líquida, os blocos apresentaram valores similares, uma vez que foram confeccionadas com o mesmo molde e na mesma máquina (Tabela 5). A NBR 6136 [11] ressalva que o bloco vazado de concreto simples, com ou sem função estrutural, deve possuir área líquida igual ou inferior a 75\% da área bruta. Portanto, os blocos pesquisados atendem a esse requisito.

Tabela 5: Media e desvio padrão das dimensões e área líquida dos BC.

\begin{tabular}{ccccc}
\hline & \multicolumn{2}{c}{ DIMENSÕES DOS BLOCOS } & \\
\hline PROPRIEDADES & RF & DESVIO PADRÃO & RCC 50\% & DESVIO PADRÃO \\
\hline Largura (cm) & 13,99 & 0,47 & 14,01 & 0,412 \\
Altura (cm) & 18,92 & 1,32 & 18,92 & 1,065 \\
Comprimento (cm) & 39,06 & 0,52 & 39,01 & 0,295 \\
Paredes longitudinais (mm) & 18,40 & 0,24 & 18,65 & 0,397 \\
Paredes transversais (mm) & 18,57 & 0,22 & 18,91 & 0,271 \\
Furos longitudinais (mm) & 158,35 & 0,37 & 158,33 & 0,341 \\
Furos transversais (mm) & 90,63 & 0,85 & 90,11 & 0,599 \\
\hline Área Líquida (mm $\left.{ }^{2}\right)$ & $25.444,06$ & - & $25.259,41$ & - \\
Área bruta (mm $\left.{ }^{2}\right)$ & $54.639,57$ & - & $54.648,37$ & \\
\hline Aliq/Abruta (\%) & 46,56 & - & 46,22 & - \\
\hline
\end{tabular}

A massa específica seca dos blocos de referência e com RCC50 são muito próximas em virtude da similaridade das massas específicas da areia industrializada e de resíduo de construção (Tabela 6). Os valores de massa específica são 13,3 e 19,7\% superiores, respectivamente, às encontradas no estudo de dosagem, indicando que o processo mecânico de compactação efetivamente proporcionou melhor entrosamento entre as partículas da matriz científica em relação ao processo manual. Este comportamento ajuda a explicar a absorção de água e de índice de vazios encontrados nos traços dos blocos descritos na sequência.

Os valores encontrados no ensaio de absorção de água indicam que o traço de referência e o RCC50 atendem aos parâmetros normativos de 10\% estabelecido na NBR 6136 [11] (Tabela 6). Devido ao processo vibroprensagem utilizado na produção dos blocos, os valores de absorção de água foram inferiores a aqueles encontrados no estudo de dosagem, porém para os blocos com RCC, estes continuam superior ao de referência, fato este justificado pela presença de materiais como cerâmica, gesso, argamassa, concreto, entre outros com maior porosidade que areia industrializada. BASTOS el al. [28] encontrou absorção de água de 16,6\% para blocos de concreto com $100 \%$ de substituição de RCC, superior ao encontrado nesse trabalho. Desta forma, o estudo de dosagem inicial (não conduzido pelo autor) se torna importante estratégia para a definição do adequado teor de substituição no traço uma vez que o excesso de RCC na mistura o torna susceptível ao não atendimento quanto a esse requisito normativo.

Os valores de índice de vazios são proporcionais aos valores de absorção de água, pois quanto menor os vazios existentes na estrutura da matriz cimentícia, menor a quantidade de poros na massa de concreto, ocasionando menor absorção de água (Tabela 6). Como esperado, o processo de vibroprensagem também foi eficaz em proporcionar uma estrutura mais coesa a matriz cimentícia, entrosando melhor seus elementos constituintes, o que provoca menor absorção de água. Os valores também são inferiores aos quantificados no estudo de dosagem. O melhor entrosamento ocasionou elevação da densidade de massa específica seca dos blocos, conforme descrito anteriormente.

Assim, o critério de absorção de água requerido para os blocos foi atendido, tornando os blocos tecnicamente, sob este aspecto, adequados para serem utilizados comercialmente, restando definir para qual classe estrutural são indicados. 
Tabela 6: Valores médios e desvio padrão para a massa específica seca, absorção de água e índice de vazios e dos blocos de referência e RCC50.

\begin{tabular}{ccccc}
\hline TRAÇO & $\begin{array}{c}\text { MASSA ESPECíFICA } \\
\text { SECA } \\
\left(\mathbf{g} / \mathbf{c m}^{3}\right)\end{array}$ & $\begin{array}{c}\text { ABSORÇÃO } \\
(\%)\end{array}$ & $\begin{array}{c}\text { ÍNDICE DE } \\
\text { VAZIOS }(\%)\end{array}$ & $\begin{array}{c}\text { MASSA ESPECÍFICA } \\
\text { REAL } \\
\left(\mathbf{g} / \mathbf{c m}^{3} \mathbf{)}\right.\end{array}$ \\
\hline RF & $2,13 \pm 0,0086$ & $8,14 \pm 0,0015$ & $17,36 \pm 0,0025$ & $2,58 \pm 0,0024$ \\
RCC 50\% & $2,07 \pm 0,0242$ & $9,89 \pm 0,0045$ & $20,50 \pm 0,0070$ & $2,61 \pm 0,0124$ \\
\hline
\end{tabular}

As resistências à compressão, aos 14 e 28 dias, dos blocos com substituição de $50 \%$ por areia de RCC e o de referência estão indicados na Tabela 7 e Figura 7. É possível perceber que houve uma redução na resistência aos 28 dias de 9,58\% em relação ao bloco de referência, não se confirmando o que se observou no estudo de dosagem onde o bloco com substituição com 50\% de RCC apresentou resistência superior ao RF. Indica-se também a necessidade do ajuste da dosagem do traço de referência uma vez que ele não foi capaz de atingir o valor mínimo de 4,0MPa para o qual o seu traço foi utilizado como referência nesse estudo.

Apesar disso, o traço selecionado é capaz de atender os requisitos normativos para blocos Classe $\mathrm{C}$ sem função estrutural. As menores resistências observadas em relação ao estudo de dosagem são devido ao fato dos valores apresentados serem os característicos e não os médios como no estudo de dosagem. Os valores encontrados nessa pesquisa se assemelham ao obtidos por MESQUITA el al. [17] em estudo de dosagem de blocos com traço na proporção de 1:22,22 com adição de $62 \%$ de RCC em substituição a areia artificial alcançou resistência de 2,9MPa. O menor valor se deve à maior quantidade de agregados utilizados no traço, bem como em relação a maior quantidade de RCC substituído no traço de referência.

Tabela 7: Resistência característica à compressão dos blocos em função do traço e idade.

\begin{tabular}{|c|c|c|c|c|c|c|c|}
\hline TRAÇO & DIAS & MÉDIA & DESVIO PADRÃO & $\Psi^{*} \mathrm{Fb} 1$ & Fbk,EST & Fbk (MPA) & $\begin{array}{l}\text { \% de DIFERENÇA } \\
\text { em relação ao RF }\end{array}$ \\
\hline $\mathrm{RF}$ & \multirow{2}{*}{14} & 3,48 & 0,09 & 3,02 & 3,38 & 3,38 & 0 \\
\hline RCC $50 \%$ & & 3,10 & 0,02 & 2,73 & 3,06 & 3,06 & $-9,5 \%$ \\
\hline $\mathrm{RF}$ & \multirow{2}{*}{28} & 3,82 & 0,13 & 3,24 & 3,55 & 3,55 & 0 \\
\hline RCC $50 \%$ & & 3,49 & 0,34 & 2,87 & 3,21 & 3,21 & $-9,6 \%$ \\
\hline
\end{tabular}

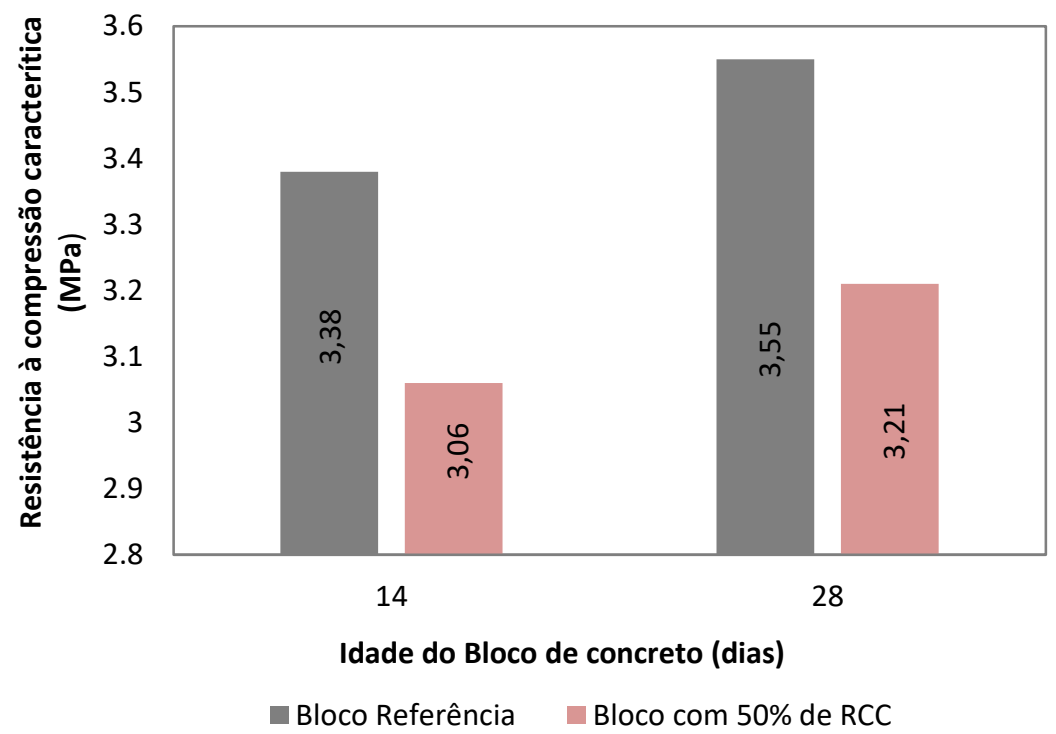

Figura 7: Resistência característica à compressão dos blocos em função do traço e idade.

\section{CONCLUSÃO}

A presente pesquisa se propôs a estudar a viabilidade técnica da substituição do agregado miúdo industrial 
por resíduo de construção civil (RCC) para a confecção de concretos secos, visando à fabricação de blocos de concreto. Buscou-se avaliar a potencialidade da produção de bloco não estrutural para fins comerciais para a cadeia produtiva da construção civil. Foram considerados os requisitos normativos de resistência à compressão axial, absorção de água, área líquida e controle dimensional, além do índice de vazios e massa específica, a fim de agregar conhecimento a pesquisa.

$\mathrm{Na}$ etapa de caracterização dos materiais da pesquisa, observou-se que massa específica do agregado miúdo reciclado é cerca de $4 \%$ maior que a massa específica do agregado miúdo industrial, sendo sua massa unitária $20 \%$ maior que a massa unitária da fração de agregado miúdo natural. A absorção de água por parte da areia reciclada $(11,1 \%)$ é superior ao da areia industrial $(1,5 \%)$, fator que influenciou o fator água/ cimento dos concretos produzidos na pesquisa para teores de incorporação superior a $50 \%$ de RCC, com vistas a adequar a trabalhabilidade da mistura.

$\mathrm{Na}$ etapa de estudo dos traços, com diferentes proporções de incorporação de resíduos de RCC em substituição a areia artificial, notou-se o que procedimento manual de moldagem dos corpos de prova conduziu a traços que não atenderam o critério de absorção de água $(\leq 10 \%)$. Apesar disso, como o processo de fabricação dos BC é feio por meio de vibroprensagem, essa não conformidade foi sanada na fase de confecção do $\mathrm{BC}$. A resistência à compressão do $\mathrm{BC}$ nos traços de 50 e $100 \%$ de substituição e no de referência foram superiores a 3,0MPa, valor indicado para blocos não estruturais Classe $\mathrm{C}$, foco da pesquisa, demonstrando a potencialidade da substituição. $\mathrm{O}$ valor de resistência tomado como referencial para estudo não foi atingido $(\geq 4,0 \mathrm{MPa})$, indicando a necessidade de ajuste do traço de referência para sanar esta não conformidade. Há uma tendência de elevação com posterior queda de resistência mecânica à medida que a quantidade de resíduos é incorporada na mistura, com resistência do traço com $50 \%$ de incorporação (adotado para a produção dos blocos) maior do que a com 100\%, corroborando com outros estudos sobre o tema de reuso de resíduos de construção civil.

$\mathrm{Na}$ etapa de produção do BC, os BC fabricados com 50\% de incorporação de resíduos e de referência atenderam a todos os requisitos físicos normativos, como absorção de água, área líquida, análise dimensional, índice de vazios e massa específica, apresentando valores inferiores aos observados nos ensaios laboratoriais, resultado do processo de produção industrial, uma vez que são confeccionados por meio de vibroprensagem. Em relação à propriedade mecânica, o $\mathrm{BC}$ apresentou resistência superior a 3,0MPa, sendo indicado, portanto para a produção de blocos não estruturais Classe C. Porém, não foi observada elevação da sua resistência em relação ao de referência como no estudo de dosagem. Pelo contrário, observou redução de 9,6\%, provavelmente resultado do maior fator a/c utilizado no traço. O BC de referência não atingiu a resistência para o qual o traço foi dosado, ratificando a necessidade de ajuste do traço de referência.

Assim, conclui-se pela viabilidade técnica do uso de agregados reciclados para produção de BC, pelo menos do ponto de vista das propriedades física e mecânicas, sendo necessário que estudos futuros abordem aspectos de durabilidade dos mesmos em condição de uso. A pesquisa contribui desta forma para o uso de materiais reciclados para a construção, incentivando à adoção de tecnologias construtivas sustentáveis, o que pode agregar qualidade dos produtos obtidos na indústria da construção civil, proporcionando redução de custos e melhoria na conservação ambiental.

\section{AGRADECIMENTOS}

Ao Instituto Federal de Mato Grosso (IFMT)/ Universidade Federal de Mato Grosso, pela disponibilização dos Laboratórios de Materiais de Construção Civil/ de Materiais. A Indústria GEOBLOCOS pela disponibilização dos insumos, mão de obra e equipamentos para a produção dos blocos.

\section{BIBLIOGRAFIA}

[1] PROGRAMA DAS NAÇÕES UNIDAS PARA O DESENVOLVIMENTO (PNUD), Buildings: investing in energy and resource efficiency, In: Towards a Green Economy: pathways to sustainable development and poverty eradication, 2012.

[2] INTERNATIONAL ENERGY AGENCY (IEA), Organization for Economic Cooperation and Development. Atlas of Energy, 2014. Disponível em: <http://energyatlas.iea.org/\#!/tellmap/-1118783123/0>. Acesso em: 18 jul. 2020.

[3] TORGAL, F.P., JALALI, S., A Sustentabilidade dos Materiais de Construção, FNAC: São Paulo, 400p, 2010 . 
[4] BOSCOV, M.E, Geotecnia Ambiental. Editora Oficina de Textos, São Paulo, 2008, 248 p.

[5] LEITE, F.C., MOTTA, R.S., VASCONCELOS, K.L., et al. "Laboratory evaluation of recycled construction and demolition waste for pavements", Construction and Building Materials, v. 25, pp.2972-2979, 2011.

[6] ORGANIZAÇÃO DAS NAÇÕES UNIDAS (ONU), Transformando Nosso Mundo: A Agenda 2030 para o Desenvolvimento Sustentável, 2015. Disponível em: https://nacoesunidas.org/pos2015/agenda2030/. Acesso em: 06 ago. 2018.

[7] LEIVA, C., SOLÍS-GUZMÁN. J., MARRERO, M., et al. "Recycled blocks with improved sound and fire insulation containing construction and demolition waste", Waste Management, v.33, pp.663-671, 2013.

[8] CARDOSO, A.A., Desempenho termo físico e mecânico de argamassas de revestimento produzidas com resíduos sólidos poliméricos, minerais e vegetais, Dissertação (Mestrado em Engenharia de Edificações e Ambiental), Universidade Federal de Mato Grosso, Mato Grosso, MT, Brasil, 2017.

[9] CALLEJAS, I.J.A., DURANTE, L.C., OLIVEIRA, A.S., "Thermal resistance and conductivity of recycled construction and demolition waste (RCDW) concrete blocks", Int. Eng. J. Ouro Preto (REM), v.70, n. 2, pp. 167-173, 2017.

[10] PAVLU, T., FORTOVA, K., DIVIS, J., et al. "The Utilization of Recycled Masonry Aggregate and Recycled EPS for Concrete Blocks for Mortarless Masonry", Materials, v.12, n.12, pp.1-18, 2019.

[11] ABNT - ASSOCIAÇÃO BRASILEIRA DE NORMAS TÉCNICAS, NBR 6136: Blocos vazados de concreto simples para alvenaria - Requisitos, Rio de Janeiro, 2016.

[12] LIMA, A.J.M., IWAKIRI, S. "Utilização de resíduos da madeira de pinus spp. como substituição ao agregado miúdo na produção de blocos de concreto para alvenaria estrutural", Ciência Florestal, v. 24, n. 1, pp.223-235, 2014.

[13] MOZER, G.Z., LOPES, A.U., WOELFFEL, A.B., Confecção de bloco de concreto para vedação com substituição parcial do agregado miúdo por serragem, Revista Científica Faesa, v. 15, n. 2, p. 29-51, jul. 2019.

[14] PADILHA, S.A, Potencialidade do uso de cinza de casca de arroz em blocos de concreto de alvenaria estrutural: Segundo NBR 6136, 2017. 123 f. Dissertação (Mestrado) - Pós Graduação em Arquitetura e Urbanismo, Universidade Federal de Pelotas, Pelotas, 2017.

[15] PRAZERES, M.S., Estudo comparativo entre blocos de concreto para Alvenaria de vedação comuns e blocos de concreto com adição de papel reciclado, 2018. 152 f. TCC (Graduação) - Curso de Engenharia Civil, Universidade Estadual do Maranhão, São Luís, 2018.

[16] ALMEIDA, L.F.S., ANACLETO, M.G., COSTA, W.A.C. Estudo da viabilidade da utilização de lodo de ETA em blocos vazados de concreto por meio da avaliação de propriedades mecânicas e acústica. 2017. 91 f. TCC (Graduação) - Curso de Engenharia Civil, Universidade Tecnológica Federal do Paraná, Curitiba, 2017.

[17] BACHETI, G.P., MAZIERO, R., GARCIA, D.P., "Elaboração e caracterização de blocos de concreto com a incorporação de resíduos de granito", Revista Gestão \& Sustentabilidade Ambiental, v. 7, n. 3, pp. 273-296, 2018.

[18] BENITTEZ, L.H., Utilização de escória de aciaria na fabricação de blocos de concreto, 2020. 103 f. Dissertação (Mestrado) - Pós-Graduação em Engenharia Civil, Universidade Federal de São Carlos, São Carlos, 2020 .

[19] GHISLENI, G., LIMA, G.T.S. "Estudo da viabilidade de reutilização da areia de fundição na produção de blocos de concreto e concreto convencional", DOI: 10.19177/rgsa.v9e02020551-570. Revista Gestão e Sustentabilidade Ambiental, Florianópolis, v. 9, n. esp., p. 551-570, mai. 2020.

[20] SILVA, M.N.G. Reaproveitamento de resíduos de vidro temperado para produção de blocos de concreto tipo vedação. 2019. 22 f. TCC (Graduação) - Curso de Engenharia Civil, Centro Universitário de Goiás - Uni - Anhanguera, Goiânia, 2019.

[21] GORSKI, D.P., CALLEJAS, I.J.A., DURANTE, L.C., et al.Impacto da adição de argamassa isolante nas propriedades termomecânicas de blocos de concreto de vedação vertical, https://doi.org/10.18607/ES201988140. E\&S - Engineering and Science, v.8, n.1, pp.25-40 2019.

[22] ROCHA, F.M.D., MELO, A.B., SILVA, E.P., et al. "Pré-moldado (bloco EVA) para alvenaria intertravada: projeto, produção, desempenho e simulação de uso em habitação social", Ambiente Construído, v.13, n.2, pp.47-60, 2013 . 
[23] COSTA, J.A., JOB, A.E., OKIMOTO, F., et al. "Análises de desempenho térmico e acústico de blocos de concreto com incorporação de borracha de pneu", In: $23^{\circ}$ CBECiMat - Congresso Brasileiro de Engenharia e Ciência dos Materiais, 23 ed, 2018, Foz do Iguaçu-PR, Brasil. Anais... Foz do Iguaçu: 23 CBECiMat, 2018. p. 2985.

[24] COSTA, J.A., Estudos de blocos de vedação com substituição parcial do agregado miúdo por borracha de pneu, 2020. 67 f. Dissertação (Mestrado) - Pós-graduação em Ciência e Tecnologia dos Materiais, Universidade Estadual Paulista "Júlio de Mesquita Filho", Presidente Prudente, 2020.

[25] BARRETO, J.M.L., COSTA, H.N., CANDIDO, L.F., et al. "Análise das propriedades físicas e mecânicas de blocos de concreto prensados sem função estrutural com incorporação de PET reciclado”, Matéria (Rio J.), Rio de Janeiro, v. 24, n. 2, e12357, 2019.

[26] GOMES, P.C.C., PEREIRA, F.A., UCHÔA, S. B.B., et al. "Obtenção de blocos de concreto com utilização de resíduos reciclados da própria fabricação dos blocos”, Ambiente Construído, Porto Alegre, v. 17, n. 3, pp. 267-280, jul./set. 2017.

[27] MESQUITA, L.C., AZEVEDO, I.D., CÂNDIDO, E.S., et al. “Análise da Viabilidade Técnica de Utilização de Resíduos de Construção e Demolição na Fabricação de Blocos de Vedação", REEC - Revista Eletrônica de Engenharia Civil, v.10, pp.30-40, 2015.

[28] BASTOS, I.A., CRUZ, L.F., WOELFFEL, A.B., "Fabricação de blocos de concreto para vedação com o uso de agregados reciclados em canteiro de obras", Revista Científica FAESA, Vitória, v. 12, n. 1, pp.52-58, mar. 2016.

[29] DANIEL, W., PIVA, J., ANTUNES, E., Análise das características físicas e propriedades mecânicas de blocos de concreto com uso de resíduos de construção e demolição (RCD), 2018. 18 f. TCC (Graduação) Curso de Engenharia Civil Revista, Universidade do Extremo Sul Catarinense, Criciúma, 2018.

[30] KOBAYASHI, V.Y.F., Análise da resistência à compressão de blocos estruturais de concreto simples com a utilização de resíduos de construção e demolição como agregado, 2018. 13 f. TCC (Graduação) - Curso de Engenharia Civil, Faculdade de Engenharia, Universidade Federal da Grande Dourados, Dourados, MS, 2018.

[31] MACHADO, J.F., "Reutilização de resíduos de construção e demolição para a fabricação de blocos de alvenaria”, Revista Engenharia em Ação UniToledo, v. 4, n. 1, pp. 47- 61, 2019.

[32] ARAÚJO, et al., "Uso de RCD na produção de blocos estruturais de concreto", In: CONGRESSO BRASILEIRO DO CONCRETO, 61, 2019. Fortaleza. Anais... Fortaleza: IBRACON, 2019. p 1-16.

[33] OLIVEIRA, I.P., CALLEJAS, I.J.A., DURANTE, L.C., "Blocos de concretos fabricados com incorporação de resíduos sólidos: Uma revisão sistemática”, E\&S - Engineering and Science, v.9, n.3, pp.36-57, 2020. https://doi.org/ 10.18607/ES2020911288

[34] ABNT - ASSOCIAÇÃO BRASILEIRA DE NORMAS TÉCNICAS. NBR NM 248: Agregados - Determinação da composição granulométrica, Rio de Janeiro, 2003.

[35] ABNT - ASSOCIAÇÃO BRASILEIRA DE NORMAS TÉCNICAS. NBR NM 45: Agregados - Determinação da massa unitária e volume de vazios, Rio de Janeiro, 2006.

[36] ABNT - ASSOCIAÇÃO BRASILEIRA DE NORMAS TÉCNICAS. NBR NM 52: Agregado miúdo Determinação da massa específica e massa específica aparente, Rio de Janeiro, 2009.

[37] ABNT - ASSOCIAÇÃO BRASILEIRA DE NORMAS TÉCNICAS. NBR NM 53: Agregado graúdo Determinação da massa específica, massa específica aparente e absorção de água, Rio de Janeiro, 2009.

[38] ABNT - ASSOCIAÇÃO BRASILEIRA DE NORMAS TÉCNICAS. NBR NM 27: Agregados -Redução da amostra de campo para ensaios de laboratório, Rio de Janeiro, 2001.

[39] ABNT - ASSOCIAÇÃO BRASILEIRA DE NORMAS TÉCNICAS. NBR 7211: Agregados para concreto - especificação, Rio de Janeiro, 2009.

[40] ABNT - ASSOCIAÇÃO BRASILEIRA DE NORMAS TÉCNICAS. NBR NM 23: Cimento Portland e outros materiais em pó - Determinação da massa específica, Rio de Janeiro, 2001.

[41] ABNT - ASSOCIAÇÃO BRASILEIRA DE NORMAS TÉCNICAS. NBR 15900-1: Água para Amassamento do concreto - Parte 1, Rio de Janeiro, 2009.

[42] DANIEL, W., PIVA, J., ANTUNES, E., “Análise das características físicas e propriedades mecânicas de blocos de concreto com uso de resíduos de construção e demolição (RCD)", Disponível em: 
<www.repositorio.unesc.net/handle/1/6528> Acesso em: 8 fev. 2020. Revista Técnico Científica de Engenharia Civil UNESC, Criciúma, pp. 1-18, dez. 2018.

[43] ABNT - ASSOCIAÇÃO BRASILEIRA DE NORMAS TÉCNICAS. NBR 12118: Blocos vazados de concreto simples para alvenaria - Métodos de ensaio, Rio de Janeiro, 2014.

\section{ORCID}

Danielle Melo Scheifer

https://orcid.org/0000-0002-4096-4205

Ivan Julio Apolonio Callejas

https://orcid.org/0000-0001-7877-7029 